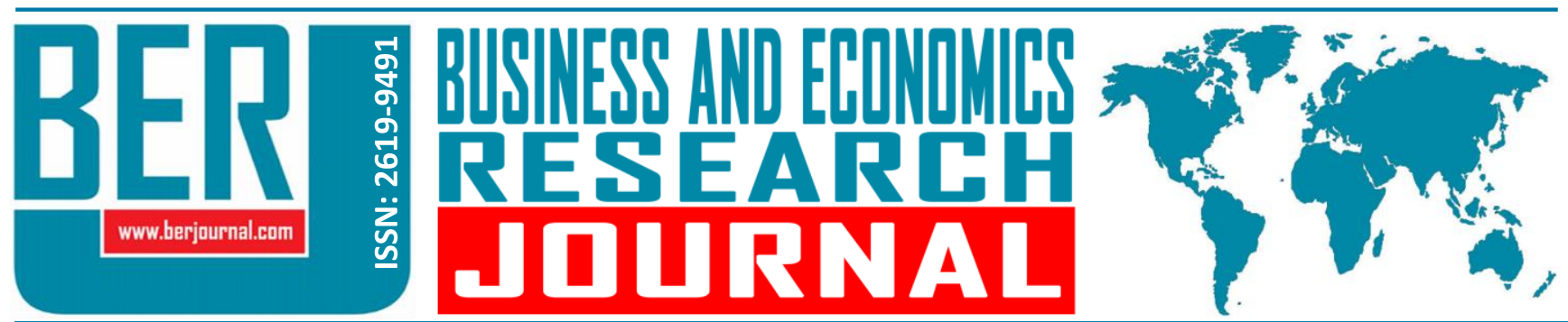

Business and Economics Research Journal Vol. 11, No. 2, 2020, pp. 385-396 doi: 10.20409/berj.2020.256

\title{
GARCH Ailesi Modelleri ve ANN Entegrasyonu ile BÍST 100 Endeks Getirisinin Volatilite Tahmini ${ }^{1}$
}

\author{
Fela Ozbey ${ }^{\mathrm{a}}$, Semin Paksoy ${ }^{\mathrm{b}}$
}

Öz: Yatırımcılar, piyasa riskinden kaçınmak için, portföy çeşitlendirmesinin yanı sıra ekonometrik modeller ile volatiliteyi en iyi şekilde modelleyerek belirsizliği azaltmaya çalışmaktadırlar. Volatiliteyi modellemek için en sık başvurulan yöntemler Otoregresif Koşullu Değişen Varyans ailesi modelleridir. Ancak son yıllarda yapılan bazı çalışmalar, Otoregresif Koşullu Değişen Varyans ailesi modellerinin Yapay Sinir Ağları algoritması ile entegrasyonundan oluşan yarı parametrik hibrit modellerin, yalın modellere göre daha iyi performans sergilediğini göstermektedir. Bundan yola çıkılarak bu çalışmada, bahsi geçen yalın ve hibrit modeller ile Borsa Istanbul 100 fiyat endeks getirisinin volatilitesi tahmin edilmiş ve hibrit modellerinin tahmin başarısı, bileşenlerinin tahmin başarısı ile karşılaştırılmıştır. Tahminlerde, veriler ile ilgili iki farklı dağılım - Normal Dağııım ve Genelleştirilmiş Hata Dağıımı - varsayımı yapılmıs ve karşılaştırmalarda Hata Kareleri Ortalaması ve Mutlak Sapma Ortalaması kriterleri kullanılmıştır. Her iki kritere göre, Üssel Genelleştirilmiş Otoregresif Koşullu Değişen Varyans - Yapay Sinir Ağları bileşkesi olan hibrit model en iyi performansı sergilemiştir. Bu bulgular doğrultusunda, finansal araçların dinamik risk analizinde hibrit modellerin sağlayabileceği üstünlüklerin değerlendirilmesi önerilmektedir.

\section{Estimation of the XU100 Index Return Volatility with the Integration of GARCH Family Models and ANN}

\begin{abstract}
To avoid market risk, besides portfolio diversification, investors are trying to model the volatility in the best way to reduce uncertainty. The most commonly used methods to model volatility are Autoregressive Conditional Heteroscedasticity family models. However, some studies published in recent years show that semi-parametric hybrid models which consist of the integration of Autoregressive Conditional Heteroscedasticity family models with the Artificial Neural Networks algorithm perform better than these simple models. In this study, the volatility of the Borsa istanbul 100 price index return is estimated by the aforementioned simple and hybrid models, and the success of the hybrid models is compared with the success of their components. Two different distributions - Normal Distribution and Generalized Error Distribution - are assumed through the estimation process. Comparisons are performed using Mean Squared Error and Mean Absolute Deviation criteria. According to both criteria, the hybrid model composed of Exponential Generalized Autoregressive Conditional Heteroscedasticity - Artificial Neural Networks performed the best. In line with these findings, it is recommended to evaluate the advantages of hybrid models in dynamic risk analysis of financial instruments.
\end{abstract}

\section{Anahtar Sözcükler:}

Volatilite, Otoregresif Koşullu Değişen Varyans Modelleri, Yapay Sinir Ağları, Hibrit Modeller, Yarı Parametrik Yöntemler, BisT 100 Endeksi

JEL: C22, C45, C52, C58, G10

Geliş : : 15 Ocak 2020

Düzeltme : 03 Mart 2020

Kabul : 23 Mart 2020

Tür : : Araştırma

Keywords: Volatility, Autoregressive Conditional Heteroskedasticity Models, Artificial Neural Networks, Hybrid Models, SemiParametric Methods, XU100 Index

JEL: C22, C45, C52, C58, G10

Received : 15 January 2020

Revised : 03 March 2020

Accepted : 23 March 2020

Type : Research

a Asst.Prof., PhD., Cukurova University, Faculty of Economics and Administrative Sciences, Department of Econometrics, Adana Turkiye, fozbey@cu.edu.tr (ORCID ID: 0000-0003-1468-6106)

b Asst.Prof., PhD., Cukurova University, Faculty of Economics and Administrative Sciences, Department of Econometrics, Adana, Turkiye, spaksoy@cu.edu.tr (ORCID ID: 0000-0003-1693-0184) 


\section{Giriş}

Finansal araçların fiyatları, politik ve ekonomik gelişmeler gibi birçok içsel ve dışsal faktörden anlık olarak etkilenmektedir. Finansal piyasalar, özellikle, öngörülemeyen ve bir teori ile açıklanamayan değişimlerin yarattığı sistematik risklere maruz kalmaktadır. Her ne kadar risklerden korunmak için çeşitlendirme yapılsa da sadece çeşitlendirme ile tüm risklerden korunmak mümkün değildir. Finansal araçların taşıdığı risklerin büyüklüğü dönemler itibarı ile farklılık gösterdiğinden bu varlıklara yapılan yatırımların takibinde, belirsizliği minimize etmek ve riskten mümkün olduğu kadar kaçınmak için, dinamik riskin takibi önem arz etmektedir.

Dinamik riskin takibinde sıklıkla kullanılan gösterge oynaklıktır. Mevcut bilgiyi kullanarak piyasa oynaklığını (volatilitesini) modellemek için en çok başvurulan parametrik yöntemler Otoregresif Koşullu Değişen Varyans (ARCH) ailesi modelleridir. Özellikle finansal piyasalarda iyi ve kötü haberlere verilen tepkiler farklı olduğundan bu piyasadaki araçların volatilitesi asimetriktir. ARCH ailesi modelleri, bu asimetriyi modellemeye uygun Eşikli (Genelleştirilmiş) ARCH (TGARCH) ve Üssel Genelleştirilmiş ARCH (EGARCH) gibi modelleri de intiva etmektedir. ARCH ailesi modellerin volatilite tahmininde bu denli yaygın kullanılmasının nedenlerinden biri de budur.

Diğer yandan, finans alanında parametrik yöntemlerle tahmin edilemeyen fiyat veya getirileriler, ağırlıklı olarak bulanık mantık ve yapay sinir ağları gibi parametrik olmayan yöntemlerle tahmin çalışmalarının literatürde yer aldığı görülmektedir. Ancak, araştırmacıların piyasa risklerini modelleme çaba ve gayretleri, konu edilen bu modellerin de ötesinde daha ileri ve güncel yöntemlerle oluşturulan modellerin önerilmesine ve kullanılmasına neden olmuştur. Son yıllarda yapılan bazı çalışmalar, ARCH ailesi modellerin Yapay Sinir Ağları (ANN) algoritması ile entegrasyonundan oluşan hibrit modellerin daha iyi performans sergilediğini göstermektedir. Bu hibrit modeller parametrik ve parametrik olmayan yöntemlerin avantajlarını bir araya getiren yarı parametrik yöntemlerdir. Bahsi geçen bu hibrit modellerin başarısı ve bu yönde yapılan çalışmaların az sayıda olması, çalışmamızın gerçekleştirilmesinde motivasyon kaynağı olmuştur. Bu nedenle ARCH ailesi modellerin ve ANN algoritmasının entegre edildiği hibrit modellerin riski modelleme başarısı Borsa İstanbul 100 (BIST 100) endeks verileri kullanılarak incelenmiştir.

Çalışmanın iç düzeni şu şekildedir: Takip eden bölümde, literatürde çeşitli finansal piyasaların volatilitelerini hibrit modeller kullanarak modellemeye çalışan çalışmalar incelenmiş ve elde ettikleri sonuçlar derlenmiştir. Üçüncü bölümde bu çalışmada kullanılan ANN algoritması, GARCH ve EGARCH modelleri ve bunların entegrasyonundan oluşan GARCH-ANN ve EGARCH-ANN hibrit modelleri kısaca tanıtılmıştır. Dördüncü bölümde BIST 100 endeksinin volatilitesi, adı geçen modeller ile tahmin edilmiş ve tahmin performansları iki farklı kritere göre karşılaştırılmıştır. Sonuç bölümünde elde edilen sonuçlar tartışılmış ve karar vericiler için önerilerde bulunulmuştur.

\section{Literatür Taraması}

Literatürde ARCH ailesi modelleri ve ANN algoritmaları kullanılarak finansal araçların fiyat, getiri ve volatilitesini modellemeye yönelik çok sayıda çalışmaya rastlansa da bu iki yöntemin bir arada kullanıldığı hibrit modeller ile yapılan çalışma sayısı oldukça kısıtıdır.

ANN algoritmasının, hisse senetlerinin fiyat modellemesi (Tektaş ve Karataş, 2004), enflasyon öngörüsü (Erilli, Eğrioğlu, Yolcu, Aladağ ve Uslu, 2010), BiST100 getirilerinin yön tahmini (Kılıç, Paksoy ve Genç, 2014), finansal krizlerin kestirimi (Aydin ve Cavdar, 2015) ve BisT100 endeks tahmini (Telli ve Coşkun, 2016) gibi Türkiye finansal piyasaları ile ilgili çeşitli uygulama alanlarında kullanıldığı görülmektedir. ARCH ailesi modellerinin ise Türkiye döviz piyasaları (Soytaş ve Ünal, 2010), BiST 100 endeksi (Tuna ve İsabetli, 2014), BiST altın endeksi (Şencan, 2017), BiST 50 endeksi (Baykut ve Kula, 2018), BísT şehir endeksi (Aşkın, 2020) gibi verilerinin volatilitesinin modellenmesinde kullanıldığı görülmektedir.

Diğer taraftan bu çalışmanın odak noktasını oluşturan ARCH ailesi modelleri ve ANN algoritmalarının entegrasyonundan oluşan hibrit modelleri kullanan nadir çalışmalar aşağıda özetlenmiş̧ir. 
Roh (2007) Üssel Ağırlıklandırılmış Hareketli Ortalama (EWMA), GARCH ve EGARCH modellerin bileşenlerini ANN algoritmasında girdi değişkeni olarak kullanılan hibrit modelleri önermiştir. Çalışmasında ANN, EWMA-ANN, GARCH-ANN ve EGARCH-ANN modellerinin volatiliteyi tahmin başarısını Kore Borsası 200 Endeksi (KOSPI 200) günlük verilerini kullanarak Mutlak Sapma Ortalaması (MAD) kriterine göre karşılaştırmıştır. GARCH-ANN ve EGARCH-ANN hibrit modellerinin diğerlerine göre daha iyi performans gösterdiği sonucuna ulaşmıştır.

Güreşen ve Kayakutlu (2008) ANN algoritmasının yanı sıra GARCH ve EGARCH modellerin ANN algoritması ile bileşiminden oluşan hibrit modelleri de kullanarak Ocak 2003-Mart 2008 dönemi için günlük veriler ile BIST 100 endeksinin volatilitesini modellemişlerdir. 4 tanesi ANN ve 8 tanesi hibrit modellerle olmak üzere toplam 12 volatilite tahmini yapmışlardır. Bu tahminlerin başarısını Hata Kareleri Ortalaması (MSE), $M A D$ ve MAD\% kriterlerine göre eğitim ve test verileri üzerinde ayrı ayrı karşılaştırmışlardır. Karşılaştırmaları sonucunda, hibrit modeller ile daha iyi tahmin performansı elde edilebileceğini ve hibrit modellerin dikkate değer olduklarını ifade etmişlerdir.

Guresen, Kayakutlu ve Daim (2011) 7.10.2008-26.6.2009 dönemini kapsayan günlük verileri ile NASDAQ endeksinin volatilitesini ANN, GARCH-ANN ve EGARCH-ANN hibrit modellerini kullanarak öngörmeye çalışmışlardır. Araştırmacılar, çok katmanlı algılama (MLP) sürecinin kullanıldı̆̆ı ANN algoritması ile daha iyi öngörü elde ettiklerini beyan etmişlerdir.

Selmi ve Achairi (2015) Tunus borsa endeksi TUNINDEX'in 02.01.2008-12.09.2012 dönemini kapsayan günlük verilerini kullanarak ANN, ARCH, GARCH, EGARCH, ARCH-M, GARCH-M ve bu modellerden oluşan hibrit modellerin volatiliteyi öngörme performanslarını Karekök MSE (RMSE), MAD\% ve Theil kriterlerine göre karşılaştırmışlar ve hibrit modellerin volatiliteyi öngörmede daha iyi performans sergilediği sonucuna varmışlardır.

Lahmiri ve Boukadoum (2015) farklı dağılım varsayımlarının hibrit modellerin öngörü performansını nasıl etkilediğini incelemişlerdir. Normal Dağıım (ND), Student-t Dağılımı, Genelleştirilmiş Hata Dağılımı (GED) varsayımları altında ARCH ailesi modelleri tahmin etmişler ve her bir modelin bileşenlerini ANN algoritmasında girdi değişkenleri olarak kullanmışlardır. Daha sonra tüm dağılım varsayımları ile tahmin ettikleri modellerin bileşenlerinin tamamını kullanarak ANN algoritmasını çalıştırmışlardır. Tüm dağılımlardan elde edilen bileşenlerin bir arada kullanıldığı EGARCH-ANN hibrit modelinin en iyi öngörülerde bulunduğunu gözlemlemişlerdir.

Lu, Que ve Cao (2016) Şangay Menkul Kıymetler Borsasının Çin Enerji Endeksinin 31.12.201310.03.2016 dönemini kapsayan verilerini kullanarak EGARCH ve GJR-GARCH modellerin öngörü performansını EGACH-ANN ve GJR-GARCH-ANN modellerinin öngörü performanslarını RMSE kriterine göre karşılaştırmışlardır. Çin enerji piyasasının kaldıraç etkisi içerdiği ve EGACH-ANN modelinin diğerlerine göre daha iyi performans sergilediği bulgularına ulaşmışlardır.

\section{Yöntem}

\subsection{ANN Algoritması}

Günümüzde bilgisayarlar hem donanım hem de yazılım açısından önemli seviyeye taşınmıştır. Bunun sonucunda, belli bir modelle ifade edilemeyen problemlerin çözümüne yönelik çalışmalarda, doğanın en zeki canlısı insanın üreme, hareket becerisi ve davranışları, düşünce ve öğrenme yapısı bilgisayar ortamında simüle edilmektedir. ANN algoritması da insanın öğrenme sürecini ve öğrenme sonrasında yeni bilgiler üretebilme özelliğine benzetim yapılmış olan algoritmalardır (Öztemel, 2003: 15).

Nöronların hesaplama işlemlerinde kullanılmasına yönelik ilk çalışmalar, McCulloch ve Pitts (1943) tarafından yirminci yüzyılın ilk yarısında gerçekleştirilmiştir. Ancak yapay ağ teknolojisindeki büyük adımların, bilgisayarların gelişmesi ile sonraki yıllarda atıldığı görülmektedir.

ANN'lerde öğrenme becerilerinin geliştirilmesi amacıyla araştırmada kullanılan veriler iki parçaya (eğitim ve test olarak) ayrılmaktadır. Eğitim verisi olarak ayrılan girdiler ile değişkenler arasındaki ilişkiler 
öğrenilir, daha sonra yeni öğrenilen bilgiler kullanılarak, ANN'nin hiç karşılaşmadığı diğer girdiler olan test verileri için tahmin yapılmaktadır. Bu nedenle, belli bir modelle ifade edilemeyen problemlerin çözümünde ANN'lerden yaygın bir şekilde alternatif karar destek sistemleri olarak yararlanılmaktadır. Dolayısı ile kesin olarak modellenemeyen risk tahmini ve optimizasyon problemlerin çözümünde tercih edilen güçlü teknikler arasında yer almaktadır.

Tipik bir ANN yapısı üç temel katmanı içermektedir. Bilgi akışı girdi katmanından başlamakta, sağa doğru gizli katmana (ara katman) ve çıktı katmanına doğru ilerlemektedir. Girdi katmanındaki her bir nöron bir değişkene karşılık gelmektedir. Girdi katmanındaki nöronlardan akan bilgi, başlangıç ağırlıkları rassal seçilerek ağırlıklandırıır ve gizli katmandaki nöronlara aktarılır. Gizli katmandaki her nöron bir önceki katmanın tüm nöronları ile ilişkilidir. Gizli katmandaki nöronlarda aktive edilen bilgiler çıktı katmanına iletilir. Bu katmandaki nöronlarda aktive edilen bilgiler de sistemin dışına çıkarııır.

Girdi katmanında başlayan bilgi akışı, çıktı katmanına doğru aşağıdaki işlemlerle ileriye doğru ilerletilmekte ve çıktı elde edilmektedir.

i. Gizli nöron net girdisi, $n e t_{h i}=\sum_{j=1}^{n} w_{i j} x_{j}+b_{1}$. Burada, $w_{i j}$, j. girdi nöronu ile i. gizli nöron arasında bağın ağılığı; $x_{j}$, j. girdi nöronundan ağa aktarılan girdi değeri; $b_{1}$, gizli katman sapma (bias) değerini ifade etmektedir. $x=$ net $_{h i}$ iken i. gizli nöron net çıktısı, out $t_{h i}=\left(e^{x}-e^{-x}\right) /\left(e^{x}+e^{-x}\right)$ şeklindedir.

Gizli katman temel ve önemli hesaplamaların yapıldığı, öğrenmenin gerçekleştiği katmandır. Öğrenme sürecinde sistem, eğitim verisi üzerinde çalısırken ağın ürettiği çıktı ile olması gereken değeri karşılaştırılarak, gözlenen farklılıkları, ağın ağrılıklarına dağıtarak minimize etmeye çalışmaktadır. Dolayısı ile bu aşamada geriye dönük (backward) işlem yapılmaktadır. Ayrıca gizli katman ile çıktı katmanına her iterasyonda veri girişi esnasında sapma payı $(b=1)$ ilave edilmektedir.

ANN'lerin eğitim performansları, başlangıçta ayrılan ve öğrenme sürecinde sistemin muhatap olmadığı test verisinden yararlanılarak ölçülmektedir. Test verilerine yönelik doğru tahminlerin sayısı veya oranı yüksek ise ağın öğrendiğine karar verilmektedir. Ağın öğrenme süreci, gerçekleşen ve gözlenenler arasındaki farkı minimum kılan ağılıkların belirlenmesi olarak ifade edilmektedir. Dolayısı ile klasik yöntemlerle modellenemeyen süreçler için etkili sonuçlar verebilmektedir.

\subsection{ARCH Ailesi Modelleri}

Engle (1982) beyaz gürültü sürecinin koşulsuz varyansı sabit iken koşullu varyansı zamana bağımlı olduğu durumlarda, bu koşullu varyansı q. sıra otoregresif süreç olarak modellemiş ve q. sıra ARCH (ARCH(q)) olarak adlandırmıştır. Süreç aşağıdaki gibi tanımlanmaktadır:

$$
E\left(\varepsilon_{t}^{2} \mid I_{t-1}\right)=h_{t}=\alpha_{0}+\alpha_{1} \varepsilon_{t-1}^{2}+\alpha_{2} \varepsilon_{t-2}^{2}+\ldots+\alpha_{q} \varepsilon_{t-q}^{2}
$$

Burada, $\varepsilon_{t} i i d\left(0, \sigma^{2}\right)$ olarak tanımlanan beyaz gürültü süreci, $\alpha_{j}$ katsayılar ve $l_{t-1}$, t-1 zamanda mevcut olan bilgi setidir.

Bollerslev (1986) ARCH(q) modeline koşullu varyansın $p$ tane gecikmeli değerlerini de ekleyerek modeli genelleştirmiştir. $\operatorname{GARCH}(p, q)$ modeli

$$
h_{t}=\beta_{0}+\beta_{1} h_{t-1}+\beta_{2} h_{t-2}+\ldots+\beta_{p} h_{t-p}+\alpha_{1} \varepsilon_{t-1}^{2}+\alpha_{2} \varepsilon_{t-2}^{2}+\ldots+\alpha_{q} \varepsilon_{t-q}^{2}
$$

olarak tanımlanmaktadır. $\beta_{i}$ ve $\alpha_{j}$ katsayılardır. ARCH modelinde beyaz gürültü sürecinden gelen hataları elde etmek için bazen çok sayıda gecikmeli terim eklenmesi gerekmektedir. GARCH modeli eklenmesi gereken gecikmeli terimlerin sayısını oldukça azaltmaktadır. Genel olarak

$$
h_{t}=\beta_{0}+\beta_{1} h_{t-1}+\alpha_{1} \varepsilon_{t-1}^{2}
$$


şeklindeki GARCH $(1,1)$ modeli koşullu varyansı modellemek için yeterli olmaktadır. Ancak ARCH ve GARCH modelleri, koşullu varyansın tüm gözlemler için pozitif tahmin edilmesini garantilememektedir. Bu nedenle, modellerin katsayılarının pozitif olması, pozitif varyans tahminleri elde etmek için gerek olmasa da, yeter koşuldur.

Nelson (1991) tarafından önerilen EGARCH modeli, koşullu varyansın negatif olmamasını garantilemenin yanı sıra iyi ve kötü haberlere verilen farklı tepkileri de tek bir denklemde modellenmesine olanak vermektedir. EGARCH modellerinde $\ln \left(h_{t}\right)$ zamanın ve $v_{t}$ nin gecikmelerinin doğrusal fonksiyonları şeklinde modellenmektedir:

$$
\ln \left(h_{t}\right)=\beta_{t}+\sum \theta_{k} f\left(v_{t-k}\right)
$$

Burada $f\left(v_{t}\right)=\gamma v_{t}+\alpha\left(\left|v_{t}\right|-E\left|v_{t}\right|\right)$ dir. GARCH modellerinde olduğu gibi $\operatorname{EGARCH}(1,1)$ modeli de genel olarak koşullu varyansı modellemek için yeterlidir. $\operatorname{EGARCH}(1,1)$ modeli

$$
\operatorname{lnh} h_{t}=\beta_{0}+\beta_{1} \operatorname{lnh}_{t-1}+\alpha_{1}\left|\frac{\varepsilon_{t-1}}{\sqrt{h_{t-1}}}\right|+\gamma_{1} \frac{\varepsilon_{t-1}}{\sqrt{h_{t-1}}}
$$

olarak tanımlanmaktadır (Kirchgässner ve Wolters, 2007: 258). Burada, $\alpha_{0}, \alpha_{1}, \beta_{1}$, ve $\gamma_{1}$ katsayılardır. $\alpha_{1}+\gamma_{1}$ olumlu ve olumsuz haberlere verilen tepkileri ölçmektedir.

\subsection{Hibrit Modeller}

Bu çalışmada kullanılan GARCH(1,1)-ANN ve EGARCH(1,1)-ANN hibrit modelleri, Roh (2007) tarafından önerilmiştir. Bu modeller ile tahmin iki aşamada yapılmaktadır. Illk aşamada zaman serisinin koşullu varyansı ARCH sınıfı modeller ile modellenerek modeldeki katsayılar (parametreler) tahmin edilmektedir. İkinci aşamada, koşullu varyansın tahmininde kullanılan değişkenler, tahmin edilmiş katsayıları ile çarpılarak ANN algoritması için girdi değişkenleri türetilmektedir. Türetilen bu girdiler (değişkenler) ile ANN algoritmasının öğrenme sürecinin kolaylaştırılması ve volatilitenin daha iyi tahmin edilmesi amaçlanmaktadır.

GARCH(1,1)-ANN modeli için ilk aşamada (3) nolu eşitlikte verilen $\operatorname{GARCH}(1,1)$ modeli ile volatilite tahmin edilmekte ve ANN algoritması için $\mathrm{x}_{1}$ ve $\mathrm{x}_{2}$ olarak adlandırdığımız girdiler

$$
\begin{aligned}
& x_{1}=\hat{\beta}_{1} h_{t-1} \\
& x_{2}=\hat{\alpha}_{1} \varepsilon_{t-1}^{2}
\end{aligned}
$$

şeklinde türetilmektedir. İkinci aşamada, bu girdiler kullanılarak ANN algoritması ile volatilite tekrar tahmin edilmektedir. Böylece, GARCH(1,1)-ANN hibrit modeli ile nihai tahmin elde edilmiş olur.

EGARCH(1,1)-ANN hibrit modelinde (5) numaralı eşitlikte verilen $\operatorname{EGARCH}(1,1)$ modelinin tahmininden sonra şeklinde tanımlanan $\operatorname{EGARCH}(1,1)$ modeli tahmin edildikten sonra ANN algoritmasında girdi olarak kullanılmak üzere $Z_{1}, Z_{2}$ ve $Z_{3}$ değişkenleri aşağıdaki şekilde oluşturulmaktadır:

$$
\begin{array}{r}
z_{1}=\hat{\beta}_{1} \operatorname{lnh} h_{t-1} \\
z_{2}=\hat{\alpha}_{1}\left|\frac{\varepsilon_{t-1}}{\sqrt{h_{t-1}}}\right|
\end{array}
$$




$$
\mathrm{Z}_{3}=\hat{v}_{1} \frac{\varepsilon_{\mathrm{t}-1}}{\sqrt{\mathrm{h}_{\mathrm{t}-1}}}
$$

Bu girdiler kullanılarak ANN algoritması ile nihai volatilite tahmini yapılmaktadır.

\subsection{Karşılaştırma Kriterleri}

Bu çalışmada, elde edilecek tahminleri karşılaştırmak için, tahmin hatalarının yayılım (değişim) ölçüsü olarak MSE ve MAD kriterleri kullanıımıştır.

MSE, gerçek değerler ile tahminleri arasındaki farkların karelerinin ortalaması şeklinde hesaplanan bir risk fonksiyonudur:

$$
\begin{aligned}
\operatorname{MSE}(\hat{Y}) & =E\left[(Y-\hat{Y})^{2}\right] \\
& =\frac{1}{T} \sum_{i=1}^{T}\left(Y_{i}-\hat{Y}_{i}\right)^{2} .
\end{aligned}
$$

Mutlak hata ortalaması (MAE) olarak da bilinen MAD, gerçek değerler ile tahminleri arasındaki farkların mutlak değerlerinin ortalaması şeklinde hesaplanan bir dağılım ölçüsüdür:

$$
\begin{aligned}
\operatorname{MAD}(\hat{Y}) & =E[|Y-\hat{Y}|] \\
& =\frac{1}{T} \sum_{i=1}^{T}\left|Y_{i}-\hat{Y}_{i}\right| .
\end{aligned}
$$

Burada $Y$, ilgili değişkeni; $\hat{Y}, Y$ değişkeninin tahminini; $i$, gözlem numarasını ve $T$ gözlem sayısını ifade etmektedir.

\section{BisT 100 Endeksinin Volatilite Tahmini}

Çalışmada 01.06.2017-02.07.2018 dönemini kapsayan BIST 100 günlük fiyat endeksi kapanış verileri kullanılmıştır. Yapılan durağanlık testlerinin sonucu, beklentilerle uyumlu olarak, serinin rassal yürüyüş süreci tarafından üretildiği yönündedir. Stokastik trendi filtrelemek amacı ile endeks serisinin logaritmik farkı alınmıştır. Böylece, durağan olan ve finans terminolojisinde getiri olarak adlandırılan yüzde değişim serisi oluşturulmuştur. Serilerin grafikleri Şekil 1'de, durağanlık testlerinin sonuçları ise Tablo 1'de verilmiştir.

Durağanlığı test etmek için Dickey ve Fuller (1981) tarafından önerilen Augmented Dickey-Fuller (ADF) ile Kwiatkowski, Phillips, Schmidt ve Shin (1992) tarafından önerilen KPSS testi kullanılmıştır. ADF testi serinin I(1) süreç tarafından üretilip üretilmediğini, KPSS testi ise I(0) süreç tarafından üretilip üretilmediğini test ettiğinden, iki testi bir arada kullanarak serinin ara bir (kesirli) bütünleşme derecesine sahip bir süreç tarafından üretilip üretilmediği de kontrol edilmiş olunmaktadır.

Şekil 1. BIST 100 Endeksi ve BIST 100 Endeksinin Getirisi

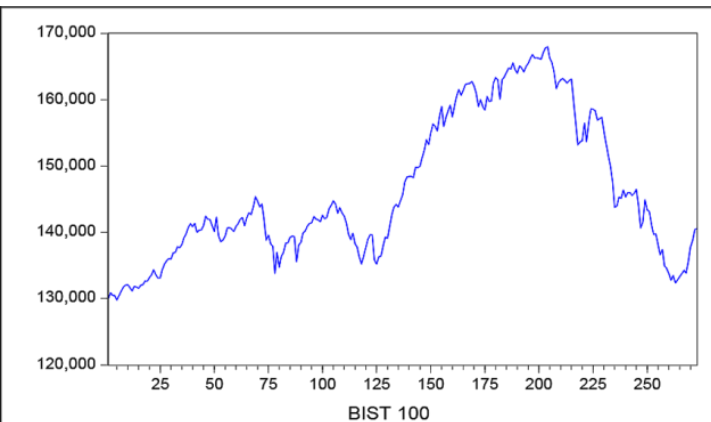

(a)

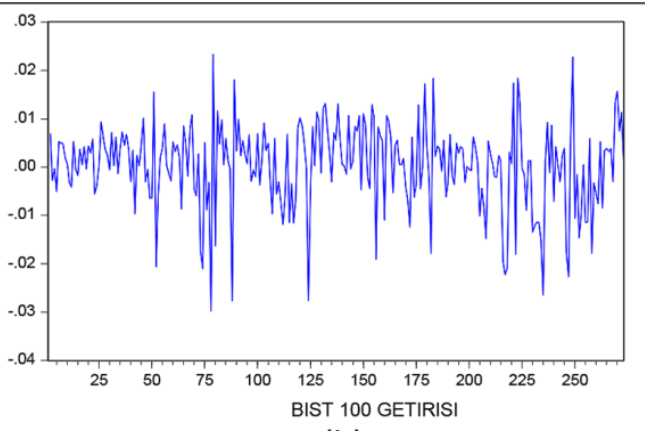

(b) 
Şekil 1 (a)'da BiST 100 fiyat endeksi serisinin grafiği; Şekil 1 (b)'de ise $\ln \left(e n d e k s_{t}\right)-\ln \left(e n d e k s_{t-1}\right)$ dönüşümü ile elde edilen BiST 100 endeksinin getiri serisinin grafiği yer almaktadır. Grafikten de açıkça görüldüğü gibi getiri serisi sıfır etrafında dalgalanmaktadır. Yani, beklentiler ile uyumlu bir şekilde, borsanın ortalama getirisi sıfırdır ve sistematik bir getirisi yoktur.

Tablo 1. BIST 100 ve BiST 100 Getiri Serileri için ADF ve KPSS Test Sonuçları

\begin{tabular}{|c|c|c|c|c|}
\hline \multirow[b]{2}{*}{ Seri } & \multirow[b]{2}{*}{ Model } & \multicolumn{2}{|c|}{ ADF } & \multirow{2}{*}{$\begin{array}{c}\text { KPSS } \\
\text { LM istatistiği }\end{array}$} \\
\hline & & $\tau$ istatistiği & $\phi$ istatistiği & \\
\hline \multirow[t]{3}{*}{ BisT 100} & Trendli ve sabitli & $-0,647724$ & 1,797147 & $0,259147^{* * *}$ \\
\hline & Sabitli & $-1,477936$ & 1,216400 & $0,809934 * * *$ \\
\hline & Sade & 0,386454 & ----- & -------- \\
\hline BIST 100 Getiri & Sade & $-15,40546 * * *$ & -------- & -------- \\
\hline
\end{tabular}

ADF testi için kullanılan modellerin tamamında gecikme Schwarz bilgi kriterine göre sıfır seçilmiştir. Gecikmesiz modeller otokorelasyon için test edilmiş, otokorelasyonlu olmadıkları için durağanlık testi bu modeller ile gerçekleştirilmiştir. Test prosedürü Dolado, Jenkinson ve Sosvilla-Rivero (1990)'da önerildiği şekilde uygulanmıştır. Getiri serisi sıfır etrafında dalgalandı̆̆ından, bu seri için durağanlık testi sadece sabitsiz ve trendsiz (arı rassal yürüyüş) model kullanılarak yapılmıştır.

Tablo 1'de yer verilen test sonuçları bir arada değerlendirildiğinde, \%1 önem düzeyinde BiST 100 fiyat endeksi serisinin I(1), BIST 100 getiri serisinin ise I(0) süreç tarafından üretildiği sonucuna varılmıştır.

BIST 100 getiri serisinin ortalama eşitliğinin gecikmeleri ile modellenip modellenemeyeceğini belirlemek için, farklı gecikmeleriyle olan otokorelasyon (AC) ve kısmi otokorelasyon (PAC) fonksiyonları tahmin edilmiştir. AC ve PAC tahminleri ve bu otokorelasyonların istatistiksel olarak anlamlı olup olmadıklarını test etmek için kullanılan $Q$ istatistikleri Tablo 2'de yer almaktadır.

Tablo 2. BiST 100 Getiri Serisinin AC, PAC tahminleri ve karşılık gelen Q İstatistikleri

\begin{tabular}{cccc}
\hline Gecikme & AC & PAC & Q \\
\hline 1 & 0,065 & 0,065 & 1,148 \\
2 & 0,085 & 0,081 & 3,141 \\
5 & 0,035 & 0,020 & 6,250 \\
10 & 0,102 & 0,112 & 12,179 \\
\hline
\end{tabular}

Tablo 2'den BiST 100 getiri serisi gözlemlerinin korelasyonsuz oldukları görülmektedir. Tablo 1 ve Tablo 2' deki sonuçlar bir arada değerlendirildiğinde BIST 100 getiri serisinin beyaz gürültü sürecinden geldiği neticesi ortaya çıktığından ortalama eşitliği modellenememektedir. Dolayısı ile risk, getiri serisinin karesi olarak tanımlanmıştır. ARCH etkisi olup olmadığını test etmek amacı ile risk serisinin farklı gecikmeleri için AC ve PAC fonksiyonları ile birlikte $Q$ istatistikleri hesaplanarak Tablo 3'te verilmiştir.

Tablo 3. BiST 100 Risk Serisinin AC, PAC ve Q İstatistikleri

\begin{tabular}{cccc}
\hline Gecikme & AC & PAC & $\mathbf{Q}$ \\
\hline 1 & 0,283 & 0,283 & $22,053^{* * *}$ \\
2 & 0,067 & $-0,015$ & $23,277^{* * *}$ \\
5 & 0,120 & 0,094 & $28,822^{* * *}$ \\
10 & 0,099 & 0,051 & $33,595 * * *$ \\
\hline
\end{tabular}

*** \%1 önem düzeyinde anlamlılı̆ı ifade etmektedir. 
Tablo 3'te BiST 100 riskinin istatistiksel olarak anlamlı otokorelasyonları olduğu, dolayısı ile ARCH etkisi içerdiği ve $A R C H$ ailesi modellerle modellenebileceği görülmektedir. Bunun üzerine ilk olarak yalın ANN, GARCH, ve EGARCH yöntemleri ile volatilite tahminleri elde edilmiştir.

ANN ile farklı mimarilerle denemeler yapılmış ve en iyi performansı sergileyen mimari yapı tercih edilmiştir. Bu tercihte kriter olarak en küçük hata kareleri toplamı kullanılmıştır. Yapılan denemelerde gizli katman sayısının iki veya üç olarak arttırılmasının, geri besleme etkisini önceki katmanlara rahat ulaştıramamasından kaynaklı olarak hata kareleri toplamının arttığı gözlemlenmiştir. O nedenle tek gizli katmanlı mimari yapı ön plana çıkmıştır. Dolayısı ile çalışmada bir girdi, bir gizli ve bir çıktı katmanından oluşan mimari yapıya ver verilmiştir. Gizli katmandaki nöronlarda hiperbolik aktivasyon fonksiyonu, çıktı katmanındaki nöronlarda birim aktivasyon fonksiyonu ve geri yayılım öğrenme süreci tercih edilmiştir. Kullanılan verinin \%70'i eğitim ve \%30'u test için ayrılmıştır.

Şekil 2. Risk Serisi ve Yalın Modeller ile Tahminleri

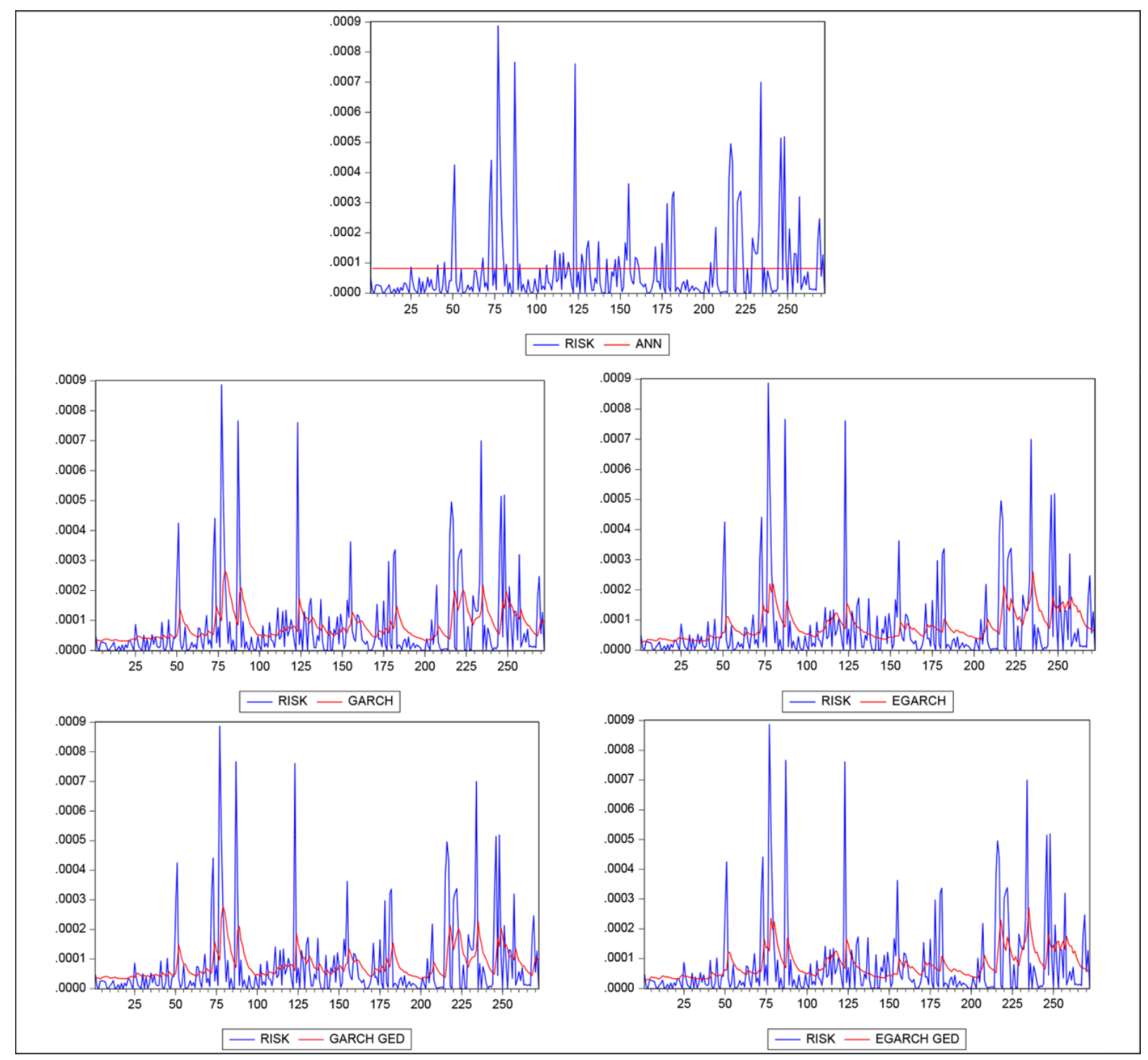

Ekonometrik modellerde, genel olarak, verinin Normal dağılımlı bir kitleden geldiği varsayılsa da, getiri serilerinin genellikle Normal dağılıma göre daha kalın kuyruklu dağıldığı bilinmektedir. Bollerslev (1987) bu kalın kuyrukluluğa dikkat çekerek GARCH modellerinin tahmininde ND yerine Student-t dağılımı varsayımında bulunularak bu modellerin tahmin başarısının arttırılabileceğini ifade etmiştir. Ancak, Nelson (1991) Student-t dağılım varsayımının sakıncalarına değinmiş ve Student-t yerine GED varsayımı altında 
tahmin yapılmasının daha uygun olacağını belirtmiştir. Bu doğrultuda, getirilerin Normal dağıımlı bir kitleden geldiği varsayımının yanı sıra, Normal dağııma göre daha kalın kuyruklu dağılan bir kitleden gelme intimalini de dikkatte alarak ARCH ailesi modelleri GED varsayımı altında da tahmin edilmiştir.

Risk serisi ve yalın modeller ile elde edilen tahminlerin ikili grafikleri Şekil 2'de gösterilmiştir. Şekildeki grafiklerde mavi çizgi getirinin karesi şeklinde tanımlanan dinamik risk serisini, kırmızı çizgi ise tahminini temsil etmektedir. Yalın modellerin veriyi modelleme performanslarının düşük olduğu; en zayıf tahminin ise ANN ile elde edildiği görülmektedir.

Tablo 4'te yalın modellerle elde edilen parametre tahminleri verilmiştir. Görüldüğü üzere, GED varsayımı altında yapılan tahminlerde her iki modelde GED parametre tahmininin 2'den küçük ve istatistiksel olarak anlamlı olması getiri serisinin normal dağılıma göre daha kalın kuyruklu dağıldığını teyit etmektedir. Ayrıca EGARCH modelinin, her iki dağılım varsayımı altında, diğer modellere göre veriyi daha iyi modellediği gözlenmiştir.

Tablo 4. ARCH Ailesi Modelleri ile Elde Edilen Parametre Tahminleri

\begin{tabular}{|c|c|c|c|c|c|}
\hline \multirow{2}{*}{$\begin{array}{c}\text { MODELLER } \\
\text { ND Varsayımı ile }\end{array}$} & \multicolumn{4}{|c|}{ Katsayılar } & \\
\hline & $\alpha_{0}$ & $\alpha_{1}$ & $\beta_{1}$ & $V_{1}$ & \\
\hline $\operatorname{GARCH}(1,1)$ & $5,10 \mathrm{E}-06 * *$ & $0,157191 * * *$ & $0,789234^{* * *}$ & & \\
\hline EGARCH $(1,1)$ & $-0,882090 * * *$ & $0,161035^{* *}$ & $0,919964 * * *$ & $-0,115683 * * *$ & \\
\hline GED Varsayımı ile & & & & & GED Parametresi \\
\hline $\operatorname{GARCH}(1,1)$ & $7,13 \mathrm{E}-06 *$ & $0,177404 * * *$ & $0,743106 * * *$ & & $1,551273 * * *$ \\
\hline EGARCH $(1,1)$ & $-1,074900 * *$ & $0,177911^{* *}$ & $0,901185^{* * *}$ & $-0,129534^{* *}$ & $1,632217^{* * *}$ \\
\hline
\end{tabular}

*,** ve *** sırası ile \%10, \%5 ve \%1 önem düzeyinde anlamlılı̆̆ı ifade etmektedir.

Literatürde ANN-GARCH ailesi hibrit modelleri de volatilite tahmininde önerilmiş ve kullanılmış olsa da (örneğin bkz., Bildirici ve Ersin, 2009), ANN ile başarılı tahminler elde edilemediğinden, çalışmada sadece GARCH(ailesi)-ANN hibrit modelleri kullanılarak yapılan volatilite tahminleri karşılaştırılmıştır. Bu doğrultuda, GARCH(1,1)-ANN ve EGARCH(1,1)-ANN hibrit modelleri ile yapılan volatilite tahmini, ND ve GED dağılım varsayımları altında gerçekleştirilmiştir. Elde edilen tahminlerin ve risk serisinin grafikleri Şekil 3'te verilmiştir.

Şekil 3. Risk Serisi ve Hibrit Modeller ile Tahminleri

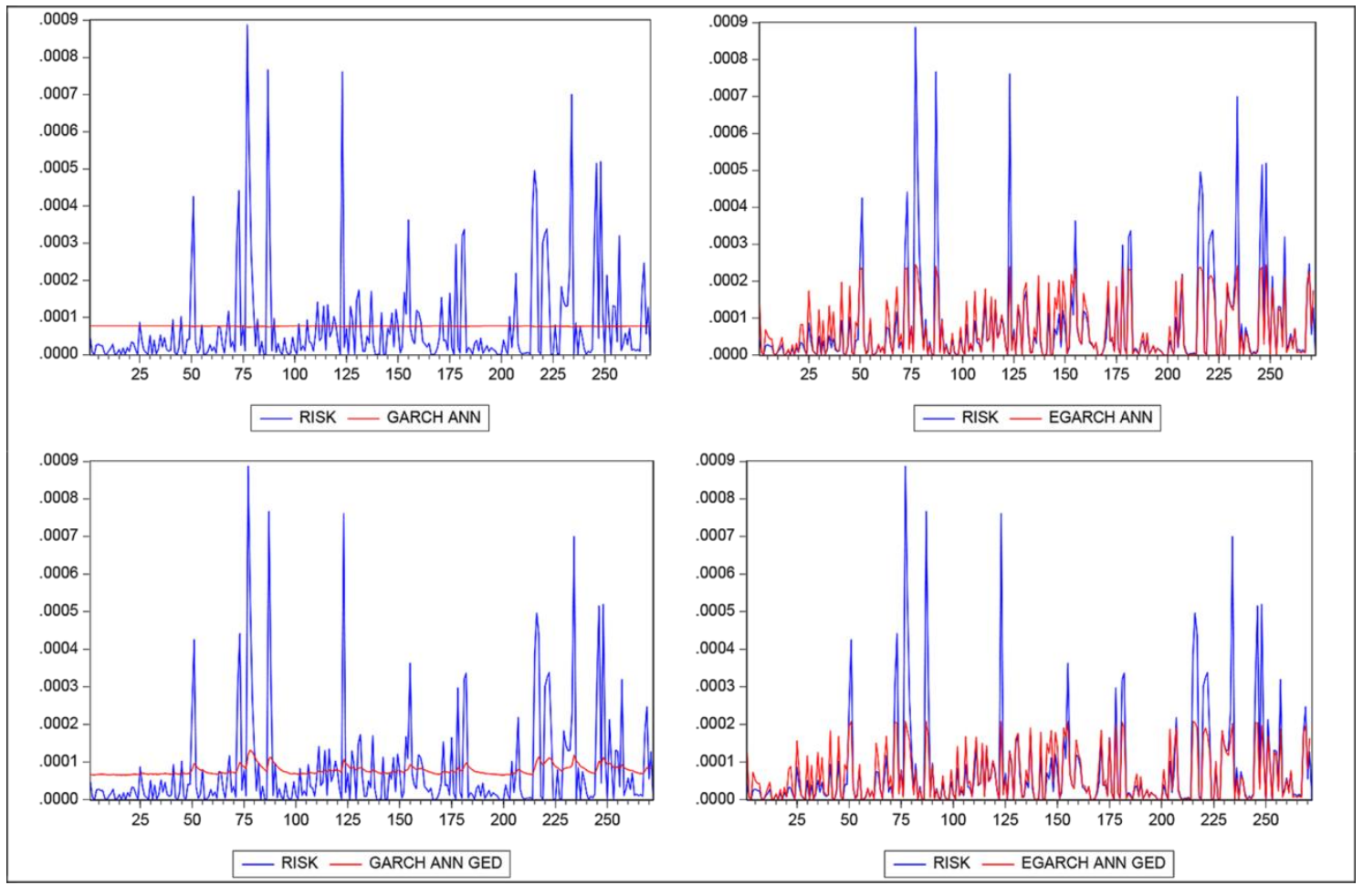


Şekil 3'te görüldüğü üzere her iki dağıım varsayımı altında $\operatorname{EGARCH(1,1)-ANN~hibrit~modeli~}$ GARCH(1,1)-ANN hibrit modeline göre daha iyi performans sergilemiştir. Bu modeller ile ilgili hesaplanan ve Tablo 5'te verilen MSE ve MAD istatistikleri de bu sonucu desteklemektedir.

Tablo 5. Tahmin Edilen Modellerin MSE ve MAD Kriterlerine Göre Performansları

\begin{tabular}{lcc}
\hline MODELLER & MSE & MAD \\
\hline ANN & Yalın Modellerin Sonuçları & \\
GARCH & 0,000000018173 & 0,000086267198 \\
GARCH (GED) & 0,000000017405 & 0,000081873715 \\
EGARCH & 0,000000017316 & 0,000081429616 \\
EGARCH (GED) & 0,000000016748 & 0,000080082808 \\
\hline & 0,000000016677 & 0,000079621752 \\
\hline GARCH ANN & Hibrit Modellerin Sonuçları & \\
GARCH (GED) ANN & 0,000000018206 & 0,000084296736 \\
EGARCH ANN & 0,000000015926 & 0,000078796468 \\
EGARCH (GED) ANN & 0,000000007151 & 0,000032922404 \\
\hline
\end{tabular}

Kriter olarak MSE ve MAD istatistikleri göz önünde bulundurulduğunda, BIST 100 endeksinin en iyi dinamik risk tahmini, normal dağılım varsayımı altında EGARCH-ANN hibrit modeli ile elde edilmiştir. Diğer yandan GARCH-ANN hibrit modelinin de GARCH modeli gibi performansının düşük kaldığı görülmüştür. Bu durum, konu edilen dönem içerisinde borsada güçlü bir kaldıraç etkisinin varlığına işaret etmektedir.

\section{Tartışma ve Sonuç}

Finansal piyasalar, sistematik riskler oluşturan birçok içsel ve dışsal faktöre maruz kalmaktadır. Çeşitlendirme yapılarak tüm risklerden korunmak mümkün olmadığından karar vericiler, dinamik riski takip etmeye ve belirsizliği olabildiğince azaltmaya çalışmaktadırlar.

Dinamik risk takibinde en sık kullanılan gösterge, finansal araçların volatilitesidir. ARCH ailesi modelleri, EGARCH gibi finansal piyasalarda iyi ve kötü haberlere verilen asimetrik tepkileri modellemeye uygun modelleri de ihtiva ettiğinden volatilite tahmininde en sık başvurulan parametrik yöntemlerdir. Ancak, son yıllarda araştırmacıların piyasa risklerini daha iyi modelleyen alternatif yöntemler bulma çabaları, farklı yöntemlerin avantajlarını bir araya getiren hibrit modellerin önerilmesini sağlamıştır. Hibrit modellerin başarısı ve bu yönde yapılan çalışmaların az sayıda olması, bu çalışmanın motivasyon kaynağı olmuştur.

Bu çalışmada, ARCH ailesi modellerin ANN algoritması ile entegre edildiği hibrit modellerin riski modelleme başarısı günlük BiST 100 endeks verileri kullanılarak incelenmiştir. Bu amaçla risk serisinin ND ve GED dağılımlarından geldiği varsayımları yapılarak GARCH ve EGARCH modelleri ile BiST 100 endeksinin volatilitesi modellenmiş ve tahmin edilmiştir. ANN algoritmasında gizli katmandaki nöronlarda hiperbolik aktivasyon fonksiyonu, çıktı katmanındaki nöronlarda birim aktivasyon fonksiyonu ve geri yayılım öğrenme süreci tercih edilmiştir.

Bir sonraki adımda GARCH ve EGARCH modellerin bileşenleri kullanılarak GARCH-ANN ve EGARCHANN hibrit modelleri oluşturulmuş ve bu hibrit modellerin tahmin başarısı, bileşenleri olan GARCH, EGARCH ve ANN tahmin başarısı ile karşılaştırılmıştır. Böylece, toplamda 9 farklı tahmin, MSE ve MAD kriterlerine göre değerlendirilmiştir.

Yapılan analizler, dağılım varsayımlarının tahmin performanslarını etkilediğini, ND varsayımı altında EGARCH-ANN hibrit modelinin diğer modellere göre daha iyi tahminler verdiğini göstermiştir. Buna ek olarak, borsadaki kaldıraç etkisinden dolayı EGARCH modelinin GARCH modeline göre dinamik riski (volatiliteyi) daha iyi modellediği ve hibrit modellerin yalın modellere kıyasla daha iyi performans sergilediği görülmüştür. Sonuç olarak, hibrit modelleri ile yapılan volatilite tahminlerinin, konuyla ilgili çalışan kişilere ve karar vericilere değerli ek bilgiler sunduğu ve yardımcı bir araç olarak kullanılabileceği görülmektedir. 


\section{Beyan ve Açıklamalar (Disclosure Statements)}

1. Bu çalışmanın yazarları, araştırma ve yayın etiği ilkelerine uyduklarını kabul etmektedirler (The authors of this article are admitted that they complied with the principles of research and publication ethics).

2. Yazarlar tarafından herhangi bir çıkar çatışması beyan edilmemiştir (No potential conflict of interest was reported by the authors).

3. Bu çalışma, intihal tarama programı kullanılarak intihal taramasından geçirilmiştir (This article was screened for potential plagiarism using a plagiarism screening program).

\section{End Notes}

1. Çalışmanın ilk versiyonu Ekim 2018, Antalya/Türkiye'de yapılan 19.Uluslararası Ekonometri, Yöneylem Araştırması ve Istatistik Sempozyumunda "Hibrit Modeller ile BiST 100 Endeksinin Dinamik Risk Tahmini" başığı ile sunulmuş ve özetler kitapçığında yer almıştır.

\section{Kaynaklar}

Aşkın, Ö. E. (2020). BIST şehir endekslerine ait volatilitenin modellenmesi. Muhasebe ve Finansman Dergisi, (85), 223242.

Aydin, A. D., \& Cavdar, S. C. (2015). Prediction of financial crisis with artificial neural network: An empirical analysis on Turkey. International Journal of Financial Research, 6(4), 36-45.

Baykut, E., \& Kula, V. (2018). Borsa İstanbul pay endekslerinin volatilite yapısı: BiST-50 örneği (2007-2016 yılları). Afyon Kocatepe Üniversitesi Sosyal Bilimler Dergisi, 20(1), 279-303.

Bildirici, M., \& Ersin, Ö. Ö. (2009). Improving forecasts of GARCH family models with the artificial neural networks: An application to the daily returns in Istanbul Stock Exchange. Expert Systems with Applications, 36(4), 7355-7362.

Bollerslev, T. (1986). Generalized autoregressive conditional heteroskedasticity. Journal of Econometrics, 31(3), 307327.

Bollerslev, T. (1987). A conditionally heteroskedastic time series model for speculative prices and rates of return. The Review of Economics and Statistics, 69(3), 542-547.

Dickey, D. A., \& Fuller, W. A. (1981). Likelihood ratio statistics for autoregressive time series with a unit root. Econometrica, 49(4), 1057-1072.

Dolado, J. J., Jenkinson, T., \& Sosvilla-Rivero, S. (1990). Cointegration and unit roots. Journal of Economic Surveys, 4(3), 249-273.

Engle, R. F. (1982). Autoregressive Conditional Heteroscedasticity with estimates of the variance of United Kingdom inflation. Econometrica, 50(4), 987-1007.

Erilli, N. A., Eğrioğlu, E., Yolcu, U., Aladağ, Ç. H., \& Uslu, V. R. (2010). Türkiye'de enflasyonun ileri ve geri beslemeli yapay sinir ağlarının melez yaklaşımı ile öngörüsü. Doğuş Üniversitesi Dergisi, 11(1), 42-55.

Guresen, E., Kayakutlu, G., \& Daim, T. U. (2011). Using artificial neural network models in stock market index prediction. Expert Systems with Applications, 38(8), 10389-10397.

Güreşen, E., \& Kayakutlu, G. (2008). Forecasting stock exchange movements using artificial neural network models and hybrid models. Paper presented at the International Conference on Intelligent Information Processing.

Kilıç, S. B., Paksoy, S., \& Genç, T. (2014). Forecasting the direction of BIST 100 returns with artificial neural network models. Int. J Latest Trends Fin. Eco. Sc., 4(3), 759-765.

Kirchgässner, G., \& Wolters, J. (2007). Introduction to modern time series analysis. Springer Science \& Business Media.

Kwiatkowski, D., Phillips, P. C., Schmidt, P., \& Shin, Y. (1992). Testing the null hypothesis of stationarity against the alternative of a unit root: How sure are we that economic time series have a unit root? Journal of Econometrics, 54(1-3), 159-178.

Lahmiri, S., \& Boukadoum, M. (2015). An ensemble system based on hybrid EGARCH-ANN with different distributional assumptions to predict S\&P 500 intraday volatility. Fluctuation and Noise Letters, 14(01), 1550001. 
Lu, X., Que, D., \& Cao, G. (2016). Volatility forecast based on the hybrid artificial neural network and GARCH-type models. Procedia Computer Science, 91, 1044-1049.

McCulloch, W. S., \& Pitts, W. (1943). A logical calculus of the ideas immanent in nervous activity. The Bulletin of Mathematical Biophysics, 5(4), 115-133.

Nelson, D. B. (1991). Conditional Heteroskedasticity in asset returns: A new approach. Econometrica, 59(2), 347-370.

Öztemel, E. (2003). Yapay sinir ağları. İstanbul: PapatyaYayıncılık.

Roh, T. H. (2007). Forecasting the volatility of stock price index. Expert Systems with Applications, 33(4), $916-922$.

Selmi, N., \& Achairi, R. (2015). Hybrid neural network model to predict stock market index: Evidence for the TUNINDEX Stock Market. Business Excellence and Management, 5(1), 79-88.

Soytaş, U., \& Ünal, Ö. S. (2010). Türkiye döviz piyasalarında oynaklığın öngörülmesi ve risk yönetimi kapsamında değerlendirilmesi. Yönetim ve Ekonomi: Celal Bayar Üniversitesi iktisadi ve İari Bilimler Fakültesi Dergisi, 17(1), 121-145.

Şencan, i. (2017). BiST altın endeksi oynaklığı analizi ve performans ölçümü. Maliye ve Finans Yazıları, 1(107), 10-24.

Tektaş, A., \& Karataş, A. (2004). Yapay sinir ağları ve finans alanina uygulanması: Hisse senedi fiyat tahminlemesi. Atatürk Üniversitesi iktisadi ve Idari Bilimler Dergisi, 18(3-4), 337-349.

Telli, Ş., \& Coşkun, M. (2016). Forecasting the BIST 100 Index using artificial neural networks with consideration of the economic calendar. International Review of Economics and Management, 4(3), 26-46.

Tuna, K., \& İsabetli, ì. (2014). Finansal piyasalarda volatilite ve Bist-100 örneği. Kocaeli Üniversitesi Sosyal Bilimler Dergisi, (27), 21-31. 